\title{
Urbanization and administrative restructuring: A case study on the Wuhan urban agglomeration
}

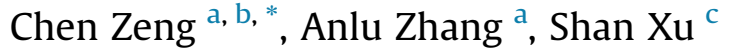 \\ ${ }^{a}$ Huazhong Agricultural University, Wuhan, 430070, China \\ ${ }^{\mathrm{b}}$ Institute of Geographical Sciences and Natural Resources Research, Chinese Academy of Sciences, 100101, Beijing, China \\ ${ }^{\mathrm{c}}$ Wuhan University, Wuhan, 430079, China
}

\section{A R T I C L E I N F O}

\section{Article history:}

Received 27 July 2015

Received in revised form

31 January 2016

Accepted 20 February 2016

Available online 3 March 2016

\section{Keywords:}

Urbanization

Administrative influence

Spatial regression

County

Wuhan agglomeration

\begin{abstract}
A B S T R A C T
Urbanization in China has been closely associated with urban sprawl, rural migration and the role of government has been more direct and powerful in setting it in motion. In 2014, the New Urbanization Planning in China has been released in which the development of urban agglomeration and smallmedium cities has been highlighted. In this context, we decompose urbanization into populationoriented and land-centered archetypes and devise spatial models in multiple strategies embedded with different spatial relations to unfold the underlying driving forces using Wuhan agglomeration as the case. In addition to the identification of major driving forces which are gross domestic product (GDP), income, fixed asset investment and the transportation construction, the major contributions of our study lie in the gauge on administrative influence, to be more specific, the status of urban district, city-level county and county, through incorporating different spatial weight matrix in different scenarios in spatial modeling. It found out that 1 ) both non-agricultural population and urban land exhibit significant spatial autocorrelation and the superiority in the city center is evident; 2) socio-economic development and transportation construction significantly influence urbanization whereas the personal income and fixed asset investment accounting for a large proportion being the most powerful factors; 3 ) different administrative status at the county level is an unneglectable factor and urban area has higher probability to expand when urban district is adjacent to county-level city; 4) the magnitude of this administrative status influence generally grows to a certain level and then reaches to a plateau. These findings provide theoretical basis for understanding the administrative dimension in new urbanization and have important policy implications on administrative adjustment and urban agglomeration.
\end{abstract}

() 2016 Elsevier Ltd. All rights reserved.

\section{Introduction}

The urbanization trajectories around the world are diversified, interwoven with distinct political framework, industrialization, globalization, secularization, gentrification and land use change process in different countries and cities (Abu \& Hay, 2013; Cox, 2013). China has undergone and is experiencing unique urbanization which raised heated and profound debate in academia and among policy-makers (Hsing, 2010; Li, 2011). In the past 30 years, albeit that the speed of urbanization in China has been strikingly fast, the discrepancy between high-level cities and county-level

\footnotetext{
* Corresponding author. Huazhong Agricultural University, Wuhan, 430070, China.
}

E-mail address: lunarzeng@gmail.com (C. Zeng). cities has rarely been attenuated and most of the mega cities has been diagnosed as over-saturated (Ni, 2013, Ni, Kresl, \& Li, 2014; Wu, Zhang, Jin, \& Deng, 2009). The New Urbanization Planning in China has been released in which the development of urban agglomeration and small-medium cities has been highlighted in 2014 (Shan \& Huang, 2013). Accompanied by the unremitted effort to seek efficiency in intra-urban development, the government and city planners have proposed to promote urban agglomeration by strengthening the connection among small-medium cities or counties (Liu et al., 2014; UNP, 2014).

In addition, the high speed of urbanization is coupled with complex administrative adjustments in China, at the county-level in particular. First, a large body of research, focused on the influence of administrative change on urban economic, political, demographic and other changes, allows a general picture to be drawn of urban administrative hierarchy and its change. Studies have been 
conducted in a number of Chinese cities such as Beijing and Guangzhou to demonstrate China's governance, power decentralization and territory adjustment, in which the change of the administrative boundary and administrative status/level are specifically incarnated (Chung, 2008; Liu \& Yang, 2012, Liu, Yin, \& Ma, 2012; Zhao, Lü, \& Woltjer, 2009). There are substantial achievements on both sides and these two types of administrative changes are generally interwoven with each other, yet we attempt to focus our research on the influence of the administrative status/level change on urbanization. In fact, China has long adopted a "Fivelevel" hierarchical administrative system as interpreted as "Country - Province - City - County- Village" (Ma \& Wu, 2013). The derivative county-level system is more complicated as it involves "county-level city", "urban district" and "county" (Cartier, 2011; Wang, 2011). County-level city is generally perceived as the county with high urbanization and is empowered to have more preferable policies. Urban district is often regarded as the clustered urban area in a city or county with more institutional restrictions from the city than county (Fan, Li, \& Zhang, 2012; Chien, 2013). Shen (2008) identified four categories of typology of urban spatial changes which are elucidated as "Governing rural area", "Rural to urban transition", and "Changes in city status", "inter-city changes. Li (2011) pointed out that strategies such as "converting counties to county-level cities (xiangaishi)" and "transforming counties to urban districts (chexian she qu)" have been popularized, but not through automatic procedures that endorses the high urbanization levels in existing counties in China. Chien (2013) explains the 'mismatch' puzzle in Kunshan and contributes its prosperity to administrative restructuring from county to county-level city. As argued by Yeh, Xu, \& Liu (2011), administration is acclaimed to be one of the important dimensions in Chinese urbanization and its impacts have been increasingly identified as the empirical studies indicate. As a matter of fact, it is argued that the decentralization of Chinese cities, while helping to enliven the local land market within the context of urbanization, industrialization and globalization, contributes to featured urban landscape with apparent gap at the county level in particular (Zuo, 2008; Wang, 2011, Wang, Fang, Wang, 2012). The emergences of "county-level city" and "urban districts" are institutional embodiment of this difference, notwithstanding the fact they are both at the same administrative level with county in the Chinese administrative hierarchy (Li, 2011; Chien, 2013). While not undermining the effectiveness of administrative adjustment at the county level, previous studies seldom involve the validation of these differences in promoting urbanization, from a spatial perspective in particular. Moreover, notwithstanding the incredible urban land expansion experienced by "county-level city" or "urban districts", the land-centered urbanization does not necessarily guarantee urbanized people, society and economy as expected (Yew, 2012). All of these would be problematic when the urbanization mechanism is explored. As a result, the in-depth investigation on the effects of administrative status/level adjustment on urbanization is indispensable and of fundamental policy implications.

Another body of research has focused specifically on examining the driving forces, dynamics and impacts of urbanization associated with urban sprawl, rural migration and infrastructure construction using remote sensing, geographical information system and spatial analysis. Compared with U.S. and European cities, most cities in China have been identified to have undergone land-dominated urbanization. Urban expansion and urban sprawl have been discerned at the city level such as Beijing, Shanghai, Guangzhou and Wuhan, at the regional level such as Pearl River delta, Yangzi river delta, or even at the national and global level though Remote Sensing (RS) and Geographical Information System (GIS) techniques (Han, Hayashi, Cao, \& Imura, 2009; Kuang,
2011; Sun, Wu, Lv, Yao, \& Wei, 2013). Furthermore, the discovery of spatial dependence in the traditional statistical calculation and the widely present spatial correlation in regional science reflect the need for incorporating spatial effect into the operational model. To achieve it, spatial regression is found to be an appropriate alternative to explore the mechanism of urban growth or regional development in a spatial explicit manner (Anselin, 2010; Yu \& Wei, 2008). With respect to the causality of urban land expansion, Deng, Huang, Rozelle, \& Uchida (2008) found income, population, the value of agricultural land and transportation costs matter in China's urban expansion. Zhou and Sun (2010) identified GDP to be the primary force of urban expansion in Pearl River delta and Seto, Güneralp, \& Hutyra (2012) used urban population and GDP to simulate global urban expansion. However, urban sprawl through infrastructure construction, the setting up of development zones and administrative adjustments, expands urban space and in turn inflates urban population size without necessarily urbanizing the overall landscape or economy (Yew, 2012). This is problematic when we attempt to measure "urbanization" as both population and land use change are essential components in this process. Shi, Li, \& Zhao (2010) consid the optimum urban population to maximize the happiness degree which is defined as the possession and/or consuming certain resources such as GDP, water, housing, etc. Peng (2011) concludes that China is at a demographic turning point from an agricultural society into an urban one, from a young society to an old one, and from a society attached to the land to one that is very much on the move. Achievements have also been made to investigate the relationship between "land urbanization" and "urbanization of population" and to figure out plans to balance their development (Wang et al., 2012). In fact, both optimizing urban land distribution and urbanizing population have been labeled as the principles of new urbanization in China (UNP, 2014). These provide the theoretical basis for decomposing urbanization into "population-oriented" and "land-centered" aspects and applying RS, GIS and spatial analysis techniques to unfold the underlying driving forces.

These previous studies inform us the importance of the administrative hierarchy and spatial interaction among cities and counties on regional urbanization. Then two important research questions are raised accordingly: how different types of counties combine with each other exhibit different spatial interaction in the process of urbanization? What is the magnitude of this spatial correlation? In response, we focus more specifically to ground our hypothesis using a case study of a representative urban agglomeration-Wuhan agglomeration in the next sections. We decompose urbanization into population-oriented and landcentered archetypes, and devise spatial modelsin multiple strategies embedded with different spatial relations to respond to questions raised above. The major function of the model is to distinguish which administrative combination at the county level is more likely to produce higher spatial interaction in the process of urbanization. Later the administrative combination with the highest spatial correlation effect is further explored with varying spatial weight to identify the magnitude. In the final section, we extend our understanding on Chinese urbanization and urban agglomeration as well as discuss the administrative influence at the county level.

In addition, to promote the new urbanization in China, the regional urban agglomeration and harmonization as well as the balance between population, resource and environment are prioritized (Fan et al., 2013; Zheng, Chen, Cai, \& Liu, 2009). In this context, using Wuhan agglomeration - a representative region in the Middle of China as the case study area, conforms to the requirements for better understanding on regional development and 
offers an updated and more detailed study of spatial interaction that incorporates the Chinese administrative hierarchy.

\section{Material and methodology}

\subsection{Study area}

Wuhan agglomeration is located in the eastern part of Hubei province, central China, along the middle reaches of Yangzi River $\left(112^{\circ} 30^{\prime}-116^{\circ} 10^{\prime} \mathrm{E}, 29^{\circ} 05^{\prime}-31^{\circ} 50^{\prime} \mathrm{N}\right)$. Apart from Wuhan City, it is composed of eight cities (towns) namely Huangshi, Erzhou, Xiaogan, Huanggang, Xianning, Xiantao, Qianjiang and Tianmen, which is renowned as " $1+8$ " Wuhan agglomeration (Fig. 1 ). There are 48 counties in Wuhan agglomeration and it covers an area of approximate $5.8 \times 10^{4} \mathrm{~km}^{2}$, most of which is in the form of plain. It has also accounted for $31.2 \%$ of the total area, $50 \%$ of the total population and 60\% of the GDP in Hubei Province. Wuhan agglomeration is chosen because it is one of the fast growing and largest urban agglomeration in China with strategic position (Tan et al., 2014). In the past 20 years, counties within Wuhan agglomeration have experienced various administrative status/level changes, which make it more suitable for our study (Han \& Wu, 2004).

\subsection{Data preparation}

Data used includes interpreted land use maps from Landsat TM images in 2010 with the spatial resolution of $30 \mathrm{~m}$. Based on the National Land Use Classification System (GB/T21010-2007) and the image processing result, the thematic land use map with eight categories-arable lands, forest, grassland, water, urban area, rural area, other construction land and unused land are generated and

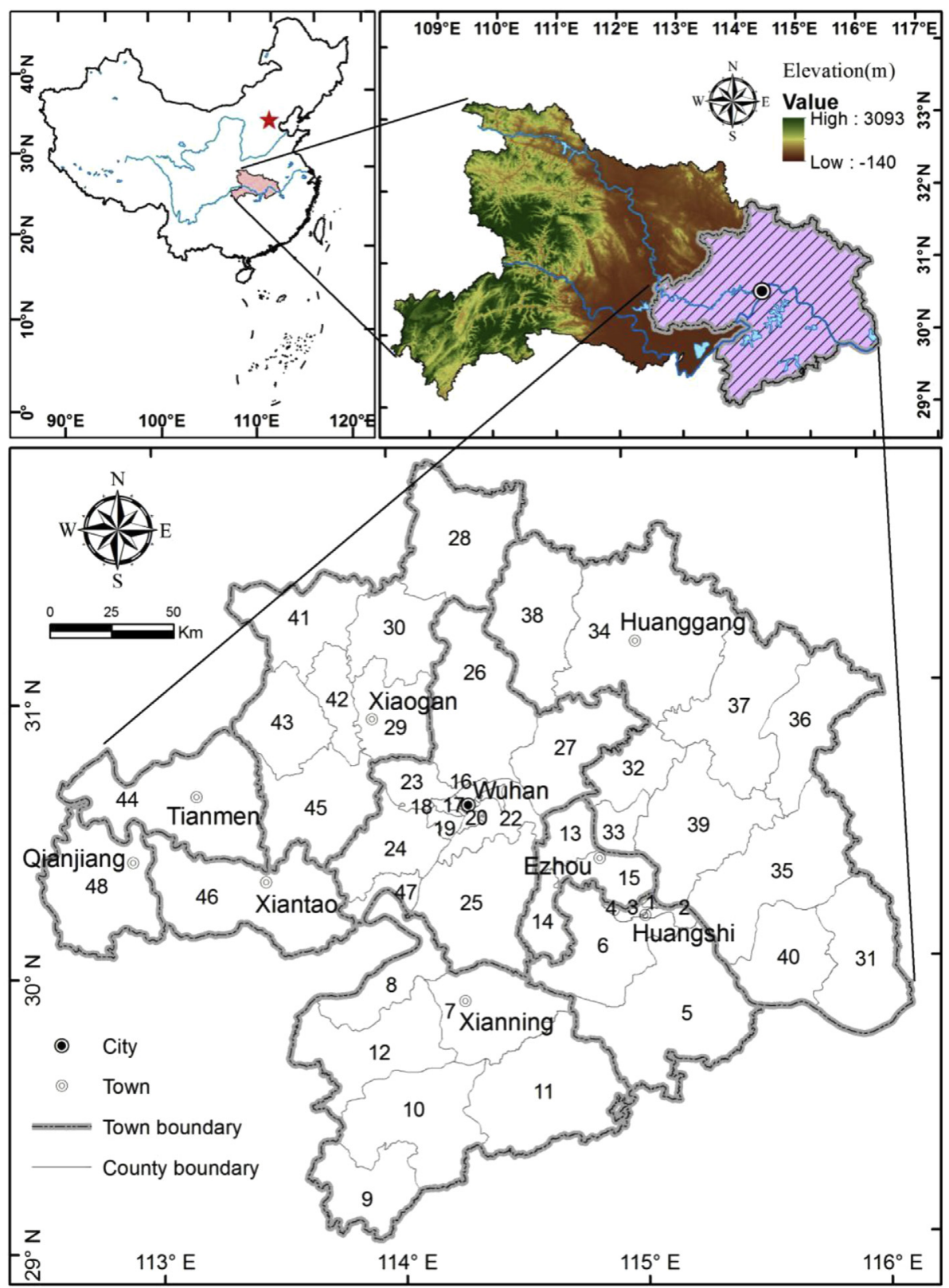

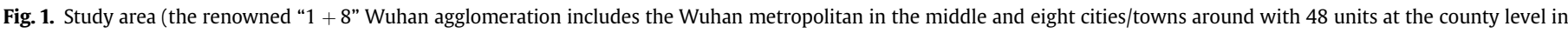
total). 


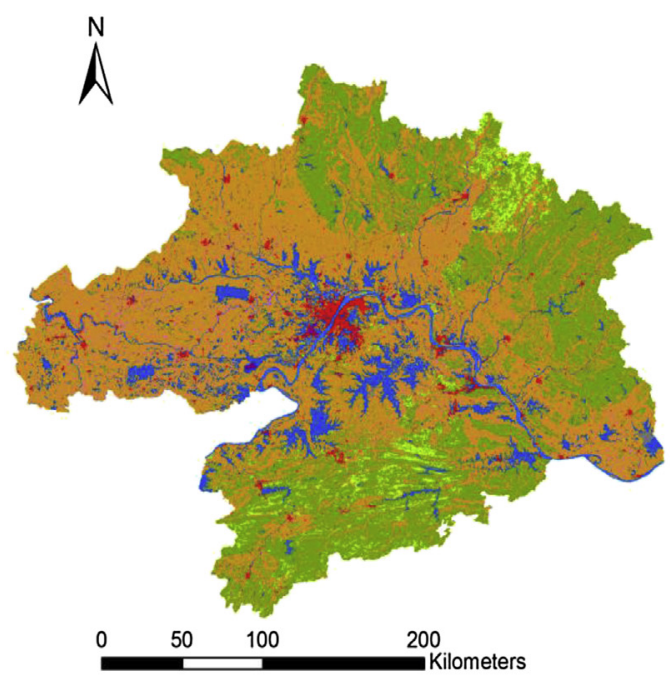

(a) Thematic land use map

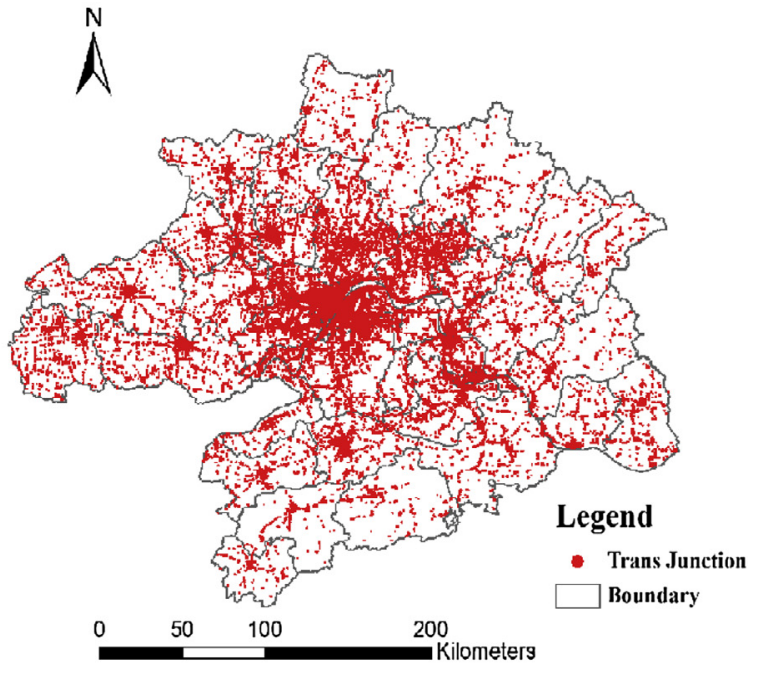

(b) The distribution of road junctions

Fig. 2. Data illustration (the left one is the thematic land use map with eight land use categories and the right one is the extracted road junctions in Wuhan agglomeration).

illustrated in Fig. 2(a). Urban area, which proves to be an important indicator for urbanization is then extracted and transformed into vector format in GIS for further analysis. The map of road junctions in China has been provided by Beijing City Lab (http://longy.jimdo. com/data-released-1/) and we extracted junction points for Wuhan agglomeration as illustrated in Fig. 2(b). We also collected population, non-agricultural population and GDP for all the counties from Hubei Yearbook (2000-2011), Wuhan City Yearbook (1996-2011), Chinese City Yearbook (1990-2011), and database from Barometer on China's Development (BOCD). Since not all the indicators are available for all the 48 counties in Wuhan Agglomeration area, we made regressions and predications to substitute the missing data.

\subsection{Methodology}

\subsubsection{Decomposition of urbanization}

As reviewed above, the demographics and the land use change in the urbanization process are the foundations of all urban history, in the developing countries such as China in particular (Abu \& Hay 2013). The harmonious development on both sides advances urbanization in a favorable manner. There upon the measurement of urbanization is disentangled into people-oriented and landcentered aspects to explore and compare the casual mechanism. Non-agricultural population density (NAPD) and the percentage of urban land (ULP) resemble the degree of people's urbanization and land urbanization correspondingly where their calculations are specified in Eq. (3.1) and Eq. (3.2).

$N A P D_{i}=\frac{N A P_{i}}{S_{i}}$

$U L P_{i}=\frac{U L_{i}}{S_{i}}$

where $\mathrm{NAP}_{\mathrm{i}}$ is the non-agricultural population in the ith county, $\mathrm{UL}_{\mathrm{i}}$ is the urban land area in the ith county and $S_{i}$ is the area of the ith county.

On accounts of the empirical studies on the primary causes of urbanization, we selected 11 potential factors namely GDP per capita (PGDP), the proportion of the second industry to GDP (PSI), the proportion of the tertiary industry to GDP (PTI), government revenue per area (PGV), fixed asset investment per area (PFAI), disposable personal income for urban residents (DPI), budget per area (PD), foreign trade export per area (PFT), foreign investment per area (PFI), retail sales of consumer goods (PTSC)and road junctions per area (PRJ) (Deng, Huang, Rozelle, Uchida, 2010; Liu, Yin, Ma, 2012; Seto et al., 2012). Because the explanatory variables are in the ratio form, we transformed these factors into the "per capita" or "per area" form correspondingly. Then we performed the stepwise regressions to screen the factors and to eliminate the multicollinearity in the models. The representative factors are specified in Eqs. (3.3-3.5).

$P G D P_{i}=\frac{G D P_{i}}{P_{i}}$

PFAI $_{i}=\frac{F A I_{i}}{S_{i}}$

$P R J_{i}=\frac{R J_{i}}{S_{i}}$

where $\mathrm{GDP}_{\mathrm{i}}, \mathrm{FAI}_{\mathrm{i}}$ and $\mathrm{RJ}_{\mathrm{i}}$ refer to gross domestic product, fixed asset investment and the number of road junctions for characterizing economic and transportation development in the ith county., $P_{i}$ is the total population in the ith county and $S_{i}$ is the area of the ith county. Other factors aforementioned are calculated in the similar ways. After collecting data and calculating the 11 potential driving factors for all the 48 counties in Wuhan agglomeration, we undertake the stepwise regression and make the Durbin-Watson (DW) test to diagnose the existence of spatial correlation.

\subsubsection{Multi-scenario establishment}

The aforementioned administrative hierarchy is illustrated in Fig. 3 with the left one explaining the composition of urban agglomeration and the right one exhibiting the 48 counties with different status/type in 9 cities or towns in Wuhan agglomeration. These three types of counties-district, county-level city and county formulate the six different spatial relationships. In order to determine whether one of these spatial interactions is more 


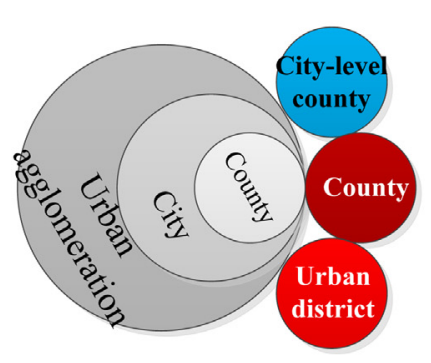

(a) Administrative level

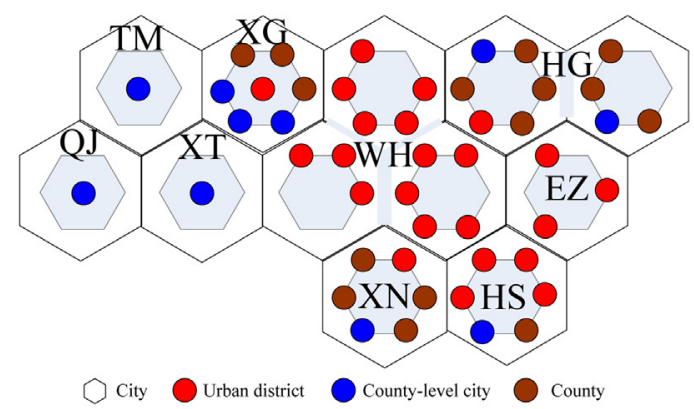

(b) administrative composition

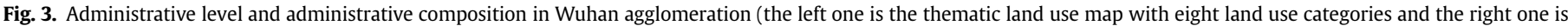
the extracted road junctions in Wuhan agglomeration).

powerful than the other in the process of urbanization, six hypotheses are described in Table 1, which forms the theoretical basis to produce the spatial weight matrix.

In order to illustrate on how the spatial weight matrices are formulated associated with these six scenarios, we take an example as follows. The left sub-figure (Fig. 4) is an example of spatial distribution of 9 unit with Ct referring to county-level city, Co referring to county and Ub referring to urban district. The right sub-figure (Fig. 4) is the illustration of the spatial matrix in six scenarios. In scenario 1 when county is adjacent to county, the value of $\lambda_{1}$ is given the value of 2 , where the value of $\lambda$ is given the value of 1 in the other spatial adjacent situations $\left(\lambda_{2}, \lambda_{3}, \lambda_{4}, \lambda_{5}, \lambda_{6}\right.$ all equal to 1 in scenario 1 ). It is the same case in scenario 2 , scenario 3 , scenario 4 , scenario 5 and scenario 6 .

We introduce the factor $\lambda$ to reflect the magnified scale of spatial relationship and six spatial weight matricies $-W_{1}, W_{2}, W_{3}, W_{4}, W_{5}$, and $W_{6}$ are thus generated for further modeling. The primary objective of the multi-scenario modeling is to give the response to the question raised in Section 1 on how different types of counties combine with each other exhibits different spatial correlation in the process of urbanization. As a result, the value of $\lambda$ can be varying as long as it is not equivalent to 1 (The value of 1 indicates the same degree of spatial interaction in all the scenarios). Here we give $\lambda$ the value of 2 and it has been amplified further when we move to the next sub-section to answer the second question on the magnitude of this spatial correlation. The detailed explanation of the different spatial weight in different scenarios is described as below.

- Scenario 1 has $W_{1}$ as the spatial contiguity based matrix, with $w_{\mathrm{ij}}=\lambda$ if $i$ and $j$ are both urban districts as spatial neighbors and $w_{\mathrm{ij}}=1$ otherwise.

- Scenario 2 has $W_{2}$ as the spatial contiguity based matrix, with $w_{\mathrm{ij}}=\lambda$ if $i$ and $j$ are both county-level cities as spatial neighbors and $w_{\mathrm{ij}}=1$ otherwise.

- Scenario 3 has $W_{3}$ as the spatial contiguity based matrix, with $w_{\mathrm{ij}}=\lambda$ if $i$ and $j$ are both counties as spatial neighbors and $w_{\mathrm{ij}}=1$ otherwise.
- Scenario 4 has $W_{4}$ as the spatial contiguity based matrix, with $w_{\mathrm{ij}}=\lambda$ if one of the spatial neighbors is urban district and the other is county-level city, and $w_{\mathrm{ij}}=1$ otherwise.

- Scenario 5 has $W_{5}$ as the spatial contiguity based matrix, with $w_{\mathrm{ij}}=\lambda$ if one of the spatial neighbors is urban district and the other is county, and $w_{\mathrm{ij}}=1$ otherwise.

- Scenario 6 has $W_{6}$ as the spatial contiguity based matrix, with $w_{\mathrm{ij}}=\lambda$ if one of the spatial neighbors is county-level city and the other is county, and $w_{\mathrm{ij}}=1$ otherwise.

\subsubsection{Spatial autocorrelation and spatial modeling}

To validate the selection of spatial regression model as well as to achieve the manifestation of spatial patterns, we employ Moran's I, a spatial autocorrelation metric that measures the degree of urban decentralization (Moran, 1950; Torrens, 2008). It is defined as

$\operatorname{Moran}^{\prime} s I=\left(\frac{n}{\sum_{i=1}^{n} \sum_{j=1}^{n} w_{i j}}\right)\left(\frac{\sum_{i=1}^{n} \sum_{j=1}^{n} w_{i j}\left(x_{i}-\bar{x}\right)\left(x_{j}-\bar{x}\right)}{\sum_{i=1}^{n}\left(x_{i}-\bar{x}\right)^{2}}\right)$

where $n$ is the number of observations in the landscape which is 48 in our case study, $x_{i}$ is the value of NAPD or ULPin the $i$ th county, $x_{j}$ is the value of NAPD or ULP for count $y j, \bar{x}$ is the mean value, and $w_{i j}$ registers the adjacency between parcel $i$ and $j$, being the rook contiguity option in our case (LeSage, 1999, LeSage \& Pace, 2008).

Spatially explicit regression models can be categorized as either spatial autoregressive models or locally linear spatial models (Crowley, 2012; Hays, Kachi, \& Franzese, 2010). In the first category, we chose the spatial lag model (SLM), which takes spatial autocorrelation into account as an explanatory variable. The objective of our study is to explore the influences of different administrative combinations at the county level on urbanization. In this sense, the spatial lag model show superiority because it only considers the

Table 1

Specification of the MRSA model in the four different scenarios.

\begin{tabular}{ll}
\hline Scenario & Hypothesis \\
\hline Scenario 1 & When county is adjacent to county, their interaction is more powerful \\
Scenario 2 & When urban district is adjacent to county, their interaction is more powerful \\
Scenario 3 & When county is adjacent to county-level city, their interaction is more powerful \\
Scenario 4 & When urban district is adjacent to urban district, their interaction is more powerful \\
Scenario 5 & When urban district is adjacent to county-level city, their interaction is more powerful \\
Scenario 6 & When county-level city is adjacent to county-level city, their interaction is more powerful \\
\hline
\end{tabular}




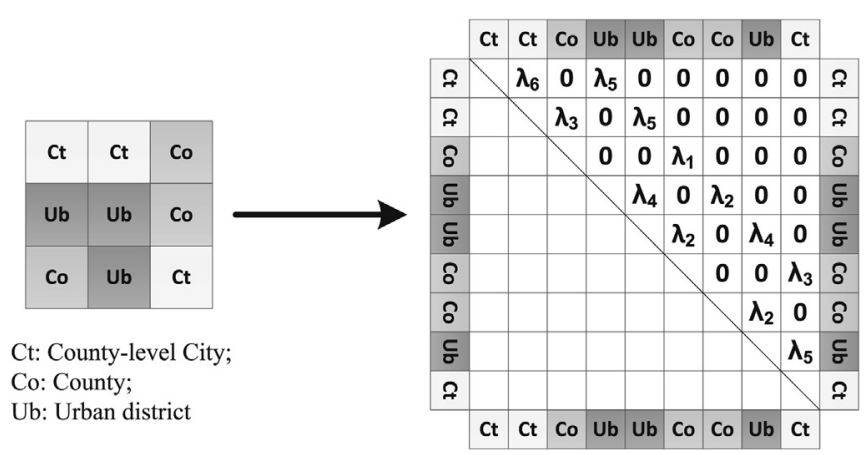

Fig. 4. Illustration of the construction of spatial weight matrix in six scenarios.

neighboring effect for the dependent variable - land-dominated urbanization, which is suitable in this study. For the $n$ counties and $p$ explanatory variables, a general form for the SLM is given in Eq.(6)

$Y=\rho W Y+X \beta+\varepsilon \varepsilon \sim N\left(0, \sigma^{2} I_{n}\right)$

whereX is an $N \times p$ matrix of explanatory variables, where $p$ is the number of independent variables. $W$ is an $N \times N$ spatial weight matrix, and $\varepsilon$ is the error. In our case, $N$ equals to 48 and pis three which refers to PGDP, PFAI, PRJ. W is defined in a flexible fashion which is corresponding to the six scenarios described above.

\section{Results}

\subsection{Urbanization in Wuhan agglomeration}

Through the stepwise regression for population based and land oriented urbanization, it is found that DPI and PFI are two primary factors accounting for the change in urban population whereas PGDP, PFAI, DPI and PRJ are revealed to be the driving forces attributed to the urban land area change. As a result, we further explore the spatial pattern of these dependent and explanatory variables.

Fig. 5 illustrates the spatial pattern of NAPD, ULP, PGDP, DPI, PFAI, PFI and PRJ where high values generally clustered in the city center with the exception of PFAI. Generally, counties in the city center and in the southeastern periphery are filled with more nonagricultural population and urban land. Urban districts and countylevel cities primarily have higher values of NAPD, ULP and PGDP, which indicates the higher level of urbanization and socioeconomic development. Conversely, counties in the outer ring of Wuhan agglomeration have the least value of PRJ which implies the underdeveloped road network. The spatial autocorrelation has also been identified in all these attributes; the values of Moran's I are $0.5626,0.4289,0.5496,0.7296,0.4148,0.5471$ and 0.5957 for NAPD, ULP, PGDP, DPI, PFAI, PFI and PRJ respectively. Both the distribution of urban population and land follows a more regionalized pattern, which validates the potential application of spatial lag model in exploring both the population-oriented and land-centered urbanization.

The first three subplots in Fig. 6 are the scatterplots between NAPD and the three explanatory variables (DPI, PFI). The correlation coefficient between NAPD and DPI is the highest (0.907) and it is 0.741 between NAPD and PFI. The last three subplots in Fig. 6 are the scatterplots between ULP and the explanatory variables (PGDP, PFAI, DPI, and PRJ). Similarly, PFAI is the most highly correlated factor with the correlation coefficient of 0.849 and PGDP is the least (0.763). The correlation coefficients between ULP and PFAI, DPI, PRJ are closely followed with the value all above 0.8 . The three types of relationships are also established among these variables: linear type (NAPD and DPI), exponential type (ULP and PGDP, ULP and DPI) and logarithm type (NAPD and PFI, ULP and PFAI, ULP and PRJ). It is revealed that the pushing force of income is continuous whereas the foreign the influence of investment on urban population would rise and then reach a plateau. The change of urban land is largely attributed to the increase of GDP and income with exponential forces and the effects of fixed asset investment and the road network on urban land similarly stagger when developed to a certain level.

\subsection{Institutional influence in different scenarios}

Table 2 shows the modeling results of population-oriented and land-centered urbanization with variable coefficient, z-probability, $\mathrm{R}^{2}$ and Durbin-Watson test (DW). The scenario of OLS refers to the traditional regression using Ordinary Least Square and Scenario 0 embraces the spatial weight with general rook contiguity option regardless of change on administrative status/level. With respect to population-oriented urbanization, both DPI and PFI are positively correlated with NAPD and DPI is more powerful to determine the non-agricultural population density. For land-centered urbanization, all these three factors are positively correlated with ULP except for PRJ. PFAI is the most powerful factor in explaining the urban expansion whereas PGDP is the least one. The R-square is higher in land-centered urbanization modeling and the result of DW test indicates the possibility of spatial autocorrelation in it. As a result, we applied the established scenarios in the aforementioned Table 1 to explore the institutional influence on urban land change. The casual influence and the accuracy vary slightly in different scenario and we list them in Table 3.

It is revealed that PGDP is more positively correlated with ULP when urban district is adjacent to county-level city and it is followed by the scenario when these two neighbors are urban district and county. Coefficient for PFAI is the largest in Scenario 2 which means the greatest influence emerges when the spatial neighbors are urban district and county, and the least influence come to the combination of urban district and county-level city. DPI has the most powerful influence when the spatial neighbors are both urban districts. In terms of PRJ, the most negatively correlated influence appears in when the spatial neighbors are urban district and county and the least comes to the situation that urban district is adjacent to urban district. The spatial autocorrelation effect is significant in all these scenarios. When urban district is adjacent to county-level city, the land dominated urbanization is more likely to appear, flowered by the condition that urban district and county are coterminous.

It is found that spatial modeling weakens the positive influence of PGDP, PFAI, DPI and the coefficients for PGDP and the spatial lag coefficient are the highest when the neighbors are urban district and county-level city, and the lowest when two urban districts are adjacent to each other. $\mathrm{R}^{2}$ is higher in spatial modeling when urban district is adjacent to county which implies a higher possibility of urban expansion in this situation. When county borders upon county, this likelihood is attenuated.

\subsection{The magnitude of institutional influence}

Based on the analysis in Section 4.2, it is revealed that the spatial interaction appear higher when county-level cities are adjacent to urban districts in the process of land-oriented urbanization (scenario 5). Hence we further explore how the causality and the fitting effect vary along with the magnified scale $(\lambda)$ (Fig. 7). The produced variations are generally divided into the ascending and descending groups. The ascending group refers to the positive increasing 


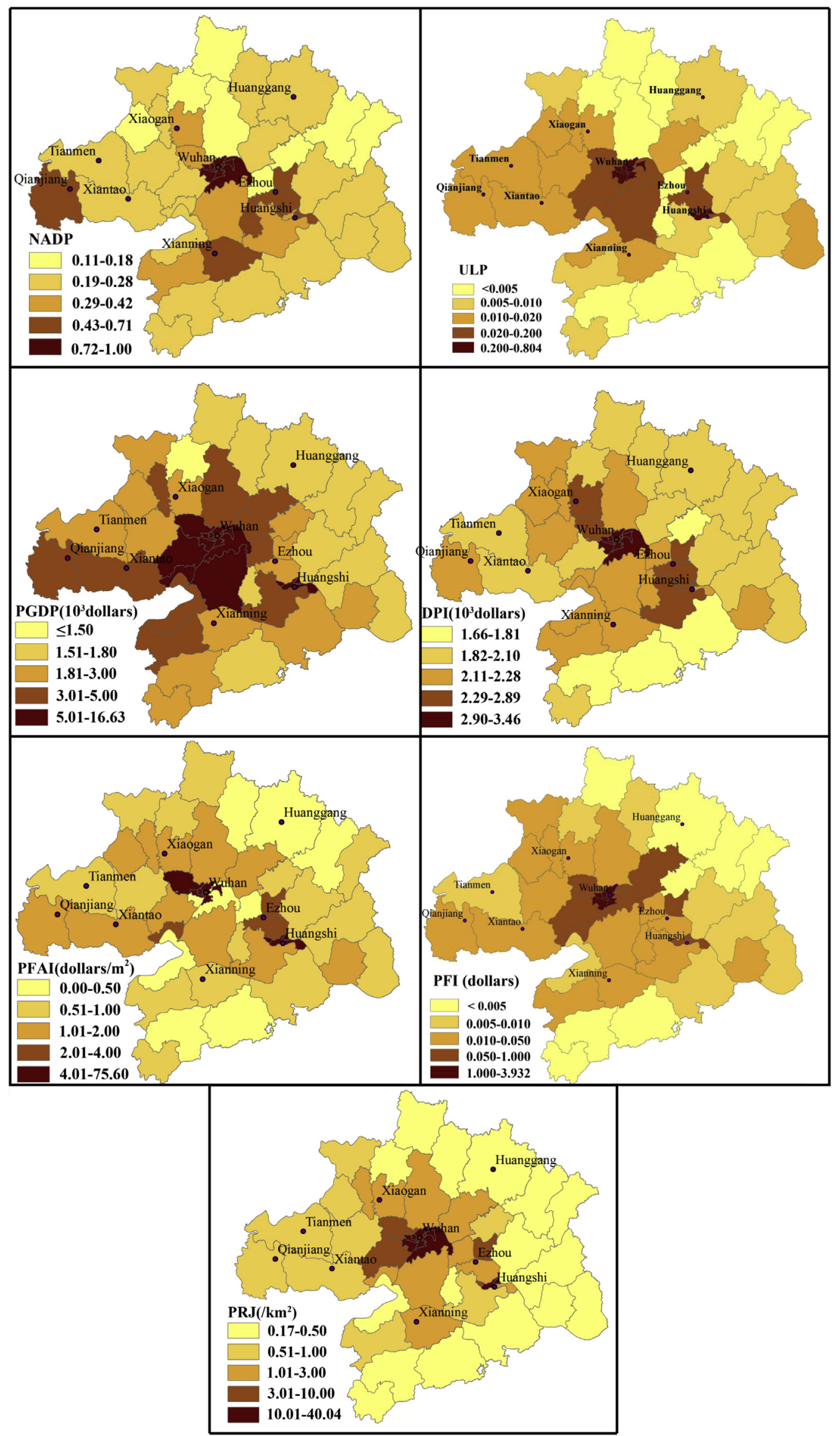

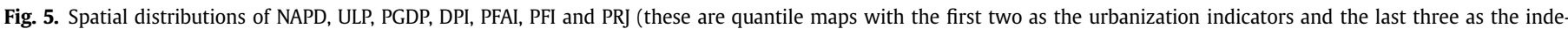
pendent variables). 


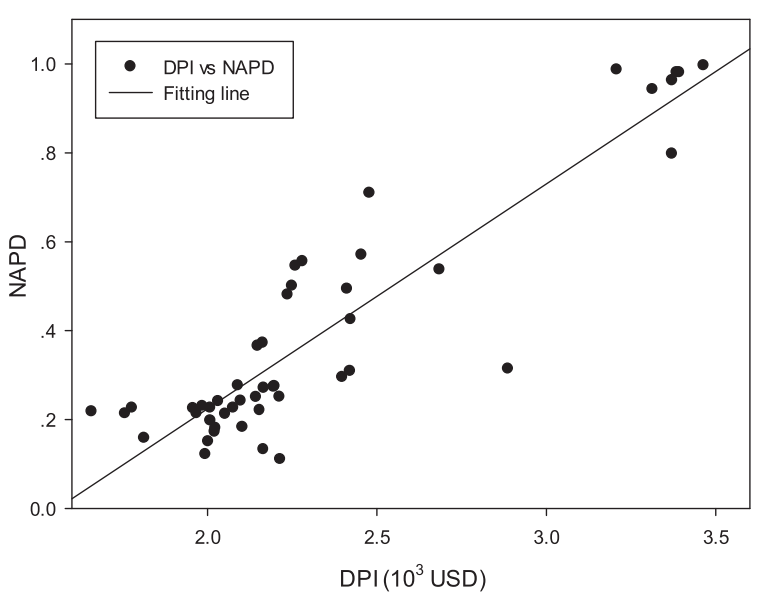

(a) NAPD and DPI

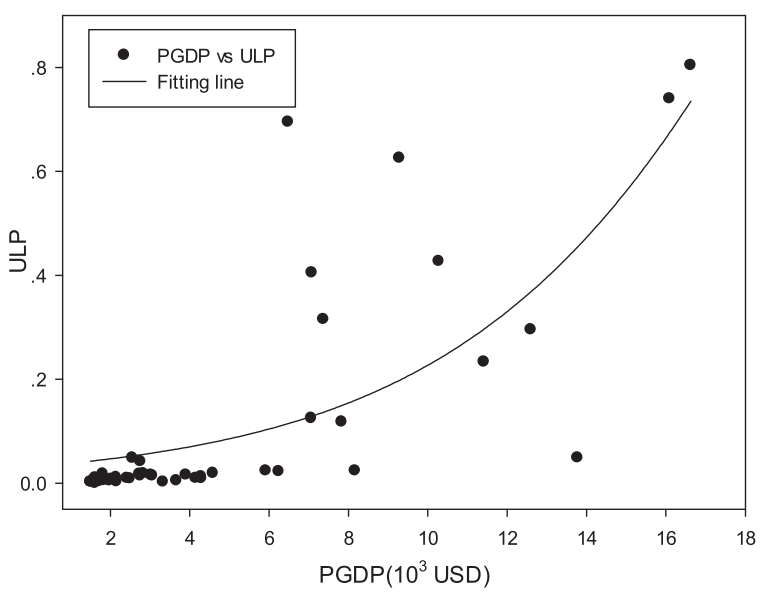

(c) ULP and PGDP

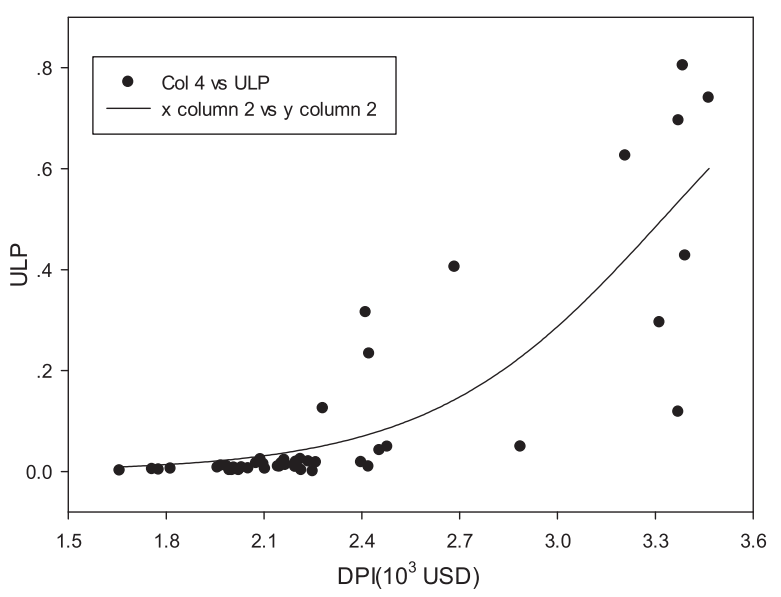

(e) ULP and DPI

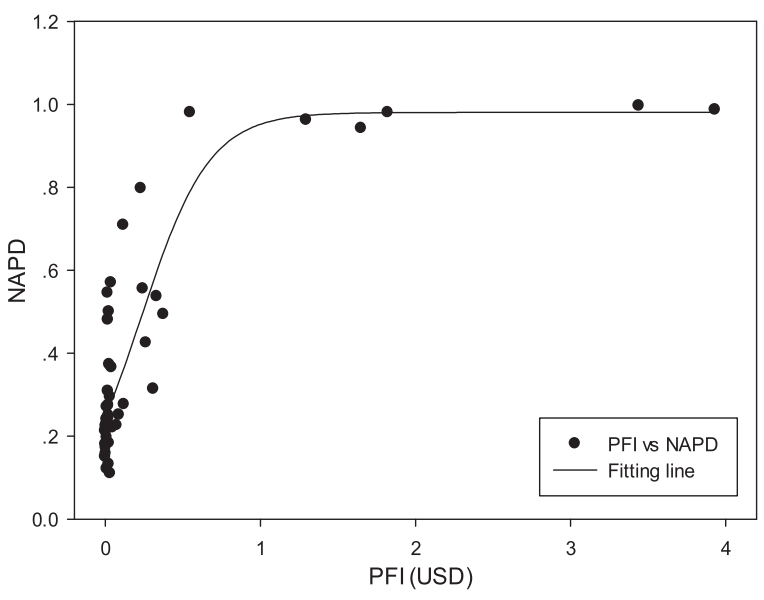

(b) NAPD and PFI

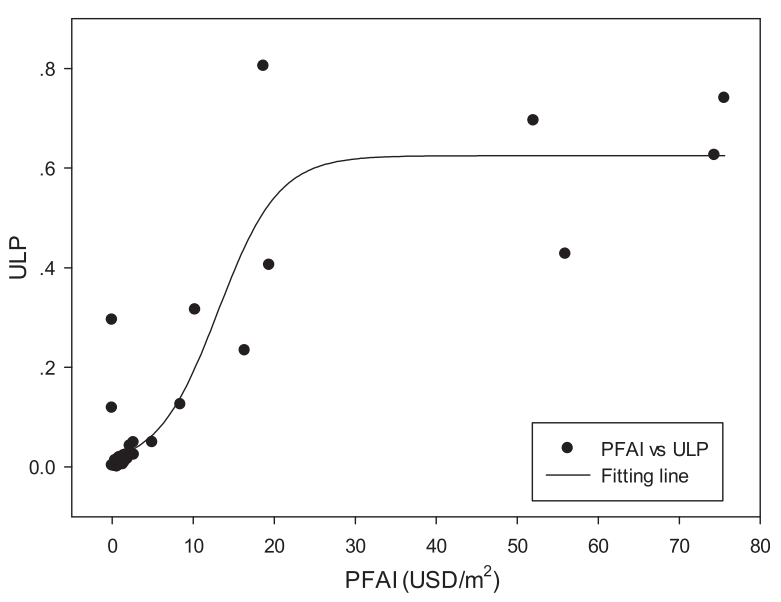

(d) ULP and PFAI

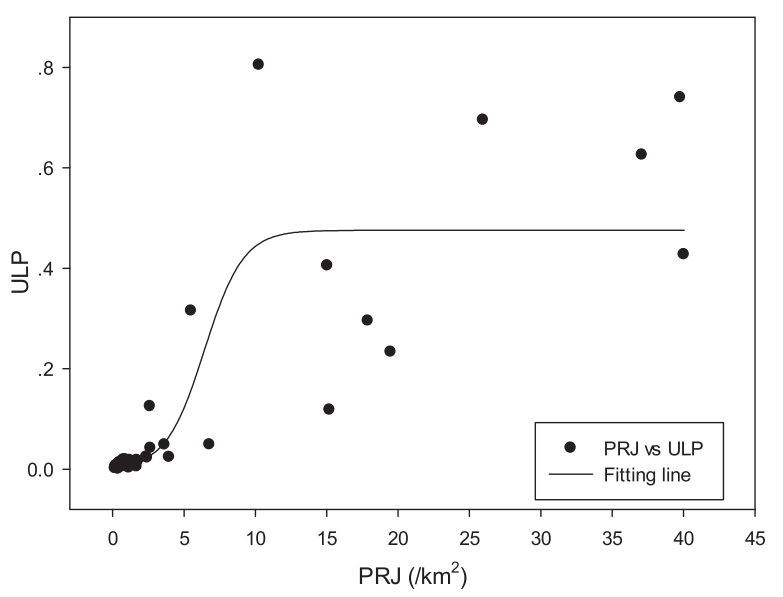

(f) ULP and PRJ

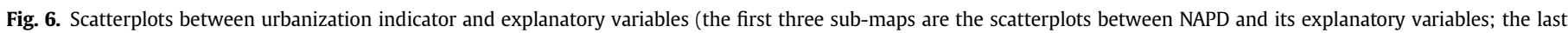
three sub-maps are the scatterplots between ULP and its explanatory variables).

relationship, where the coefficient of PGDP, the constant term and the spatial factor as well as R-square all falling into this category. In particular, the coefficient of PGDP, the constant term and the spatial factor all present logarithmic growths along with the increase of $\lambda$. It implies that PGDP has more influence on urban expansion when the spatial effects between county-level city and urban district are amplified. Yet the magnitude of these influences tends to be stable when $\lambda$ reaches to a certain level. On the contrary, the coefficients of PFAI, DPI and PRJ as well as AIC demonstrate negative decreasing relationships. The influence of PFAI and DPI on its neighbors 
Table 2

Regression in OLS.

\begin{tabular}{lllllll}
\hline NAPD & & & & & \\
\cline { 1 - 1 } \cline { 5 - 6 } Variable & Coefficient & Z-probability & & Variable & Coefficient & Z-probability \\
\hline DPI & 0.7760 & 0.0000 & PGDP & 0.2816 & 0.0000 \\
PFI & 0.1817 & 0.0000 & PFAI & 0.8519 & 0.0000 \\
& & & DPI & 0.4141 & 0.0000 \\
& & & PRJ & -0.4988 & 0.0000 \\
$\mathrm{R}^{2}: 0.8385$ & DW: 2.001 & & & $\mathrm{R}^{2}: 0.8628$ & DW: 1.618 & \\
\hline
\end{tabular}

declined with a logarithmic pattern when we amplified the spatial effect and the coefficient is also stable when $\lambda$ reached around 18. The influence of PRJ peaks when $\lambda$ equals to 3 , with the following declining trend with slight fluctuations.

\section{Discussion and policy implication}

We extend our discussion by digging beneath the populationoriented and land-centered urbanization process and the underlying driving forces that have important policy implication-relating to institutional framework, economic and urban planning, and socio-economic development.

First, as stated before, urbanization in China has been closely associated with urban sprawl, rural migration a nd the role of government has been more direct and powerful in setting it in motion (Abu \& Hay, 2013; Seto et al., 2012). For example, 13 development zones have been established in Wuhan metropolitan area in the past 20 years and the area of Jian ChengQu (JCQ) has grown from 180 to $500 \mathrm{~km}^{2}$ in the period from 1985 to 2010 according to the Wuhan Statistical Yearbook 2013 (Zeng, Liu, Stein, \& Jiao, 2015). JCQ is defined as the area affected by construction in urban areas and has been collated and reported by NBSC (Socioeconomic Statistical Yearbook for China's Counties and Cities) since the early 1980s (Deng et al., 2010). However, the expanding urban area is mostly around the periphery of the city center, while other cities or towns in urban agglomeration lag behind to a great extent (Ali \& Zhao, 2008; Wang et al., 2013). Moreover, there is a substantial proportion of floating population in urban areas with rural Hukou in Wuhan in the context of dual-track household registration system, though not as striking as the rural migration in Beijing and Guangzhou (Chan, 2010a,b, 2012). Without urbanized identification, most of them are accommodated in "chengzhongcun"or ghettos and have been segregated in the city, which contributed to the high population density in the city center whereas remarkable discrepancy emerges in other counties (Henderson, 2010). A policy implication to address these problems is that, as the new-type urbanization planning implies, the inter-urban development and the advancement of urban agglomeration are expected to be strengthened, at finer scales such as county in particular (UNP, 2014). There should also be greater scope to control urban sprawl and balance the socio-economic development among different counties through the intervention of the stronger hand tiers of government (Yang, Song, \& Lin, 2014).

Second, urbanization in China has been driven by socioeconomic and transportation development, and realized by institutional adjustment in many cases. Institutional restructuring in China involves entrepreneurial commitment by local government to competitiveness yet with reduced balancei n resource allocation and welfare provision (Lin \& Yi, 2011, Lin, Li, Yang, \& Hu, 2014). In Wuhan agglomeration, counties have experienced administrative adjustments involving boundary change and change in the status/ level, with the latter one seldom been recognized and investigated (Xu, 2012). We then raise the question: how the changes in administrative status/level influence urbanization process and what the magnitude is as discussed in the first section. The results of spatial regression confirmed that 1 ) the factors-PGDP, DPI, PFAI, PFI and PRJ are correlated with urbanization with DPI the most powerful in population based type and PFAI in land oriented one; 2 ) the influences of different administrative status exist and when county-level city and urban district are adjacent, urban area has higher probability to expand. This in turn affirms the effect of administrative change as we introduced that county-level city is generally the county with higher degree of urbanization than and county. It also provides theoretical basis to determine whether certain counties are supposed to be upgraded or transformed to county-level city or urban districts as the administrative adjustments such as the aforementioned"converting counties to countylevel cities (xiangaishi)" and "transforming counties to urban districts (chexian she qu)" have been popularized in recent years (Chien, 2013). We further examine the magnitude of administrative influence on the driving factors and fitting effect in the scenario with urban district and county-level neighbors. This result would be beneficial for policy-makers to make priorities for curbing urban expansion and make decisions on socio-economic restructuring and transportation construction to advance urbanization.

Thirdly, as implicated in the new urbanization planning, the spatial interaction of counties has been essential to realize the regional urbanization (UNP, 2014). The changing urban structure in Chinese cities did not follow the Western theory that posited market-driven and spontaneous growth. Institutional fragmentation and administrative hierarchy have increasingly functioned with the adoption of a land leasing system and the growing importance of local government power (Chung, 2008).

Table 3

Spatial modeling in different scenarios.

\begin{tabular}{|c|c|c|c|c|c|c|}
\hline Scenario & & PGDP & PFAI & DPI & PRJ & S (spatial factor) \\
\hline \multirow[t]{2}{*}{ Scenario 0} & Coefficient & 0.2483 & 0.8453 & 0.2827 & -0.5067 & 0.2970 \\
\hline & Z-probability & 0.0070 & 0.0000 & 0.0212 & 0.0072 & 0.0289 \\
\hline \multirow[t]{2}{*}{ Scenario 1} & Coefficient & 0.2488 & 0.8452 & 0.2832 & -0.5057 & 0.2929 \\
\hline & Z-probability & 0.0070 & 0.0000 & 0.0222 & 0.0073 & 0.0320 \\
\hline \multirow[t]{2}{*}{ Scenario 2} & Coefficient & 0.2491 & 0.8482 & 0.2784 & -0.5125 & 0.3090 \\
\hline & Z-probability & 0.0064 & 0.0000 & 0.0218 & 0.0064 & 0.0213 \\
\hline \multirow[t]{2}{*}{ Scenario 3} & Coefficient & 0.2484 & 0.8458 & 0.2833 & -0.5075 & 0.2960 \\
\hline & Z-probability & 0.0069 & 0.0000 & 0.0203 & 0.0071 & 0.0280 \\
\hline \multirow[t]{2}{*}{ Scenario 4} & Coefficient & 0.2455 & 0.8451 & 0.3055 & -0.5026 & 0.2550 \\
\hline & Z-probability & 0.0088 & 0.0000 & 0.0133 & 0.0083 & 0.0599 \\
\hline \multirow[t]{2}{*}{ Scenario 5} & Coefficient & 0.2552 & 0.8418 & 0.2592 & -0.5063 & 0.3340 \\
\hline & Z-probability & 0.0047 & 0.0000 & 0.0334 & 0.0065 & 0.0118 \\
\hline \multirow[t]{2}{*}{ Scenario 6} & Coefficient & 0.2484 & 0.8454 & 0.2831 & -0.5068 & 0.2960 \\
\hline & Z-probability & 0.0070 & 0.0000 & 0.0210 & 0.0072 & 0.0297 \\
\hline
\end{tabular}




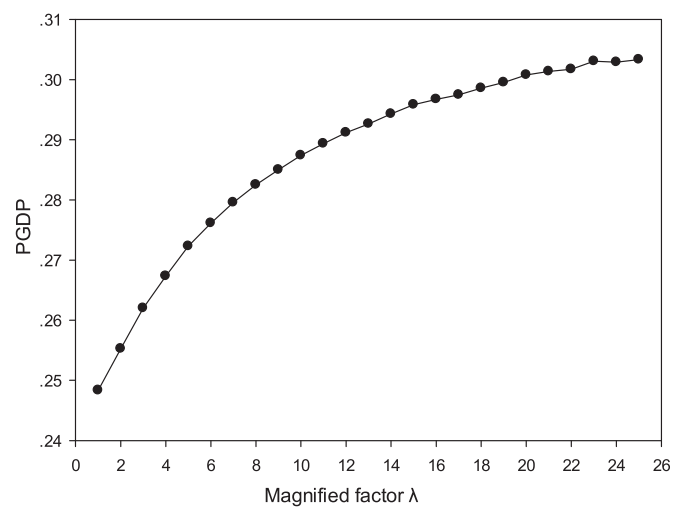

(a) The correlation coefficients of PGDP

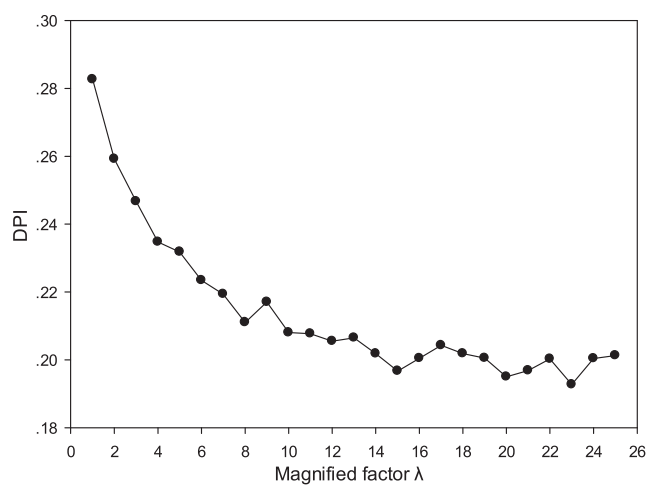

(c) The correlation coefficients of DPI

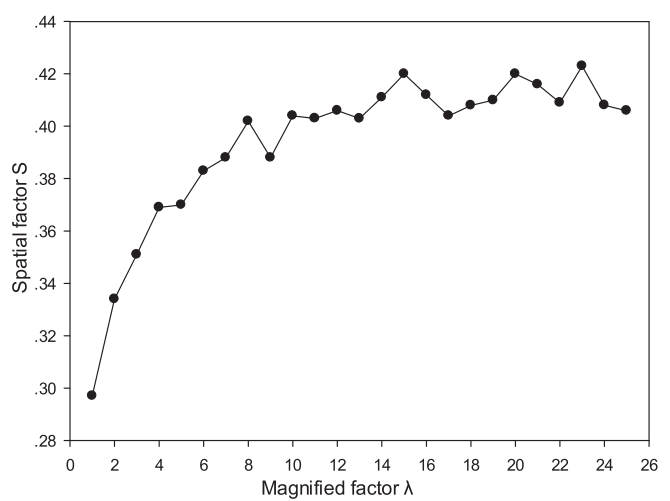

(e) The correlation coefficients of spatial factor $\mathrm{S}$

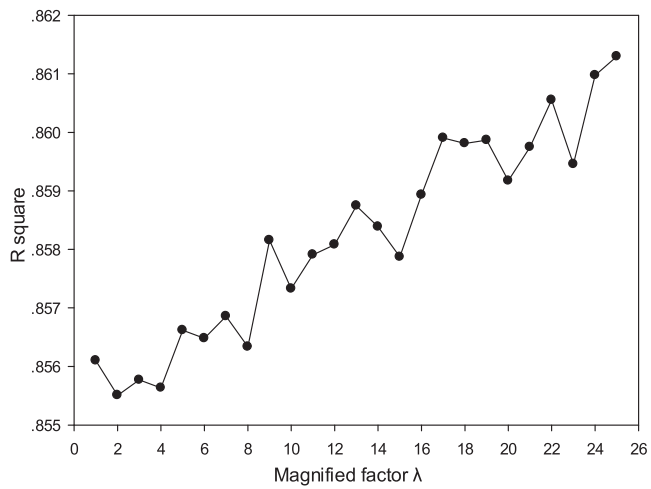

(g) R-square

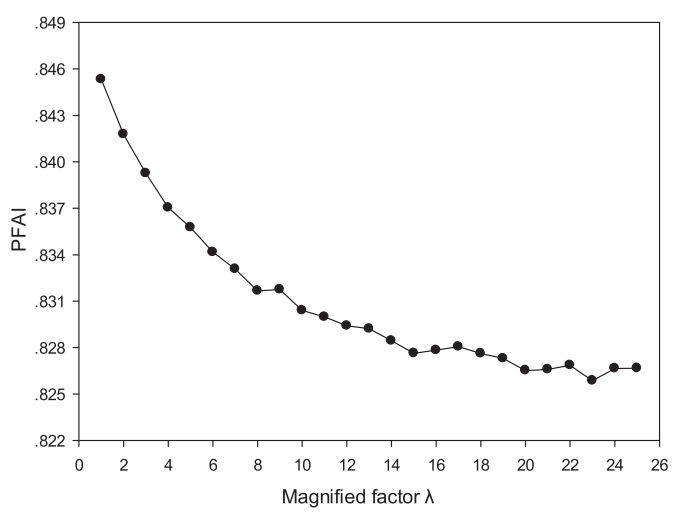

(b) The correlation coefficients of PFAI

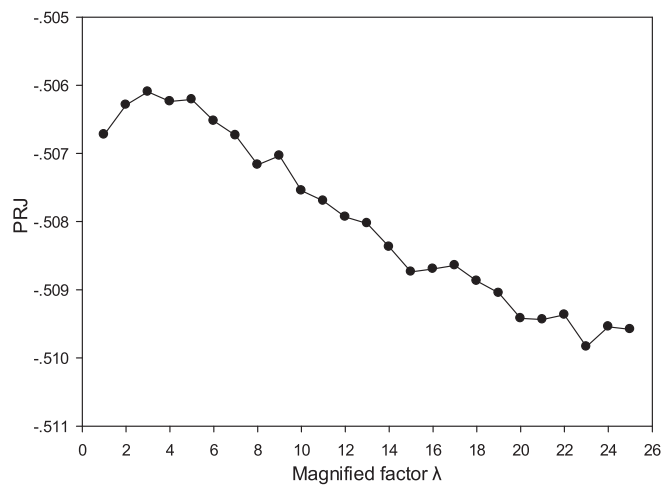

(d) The correlation coefficients of PRJ

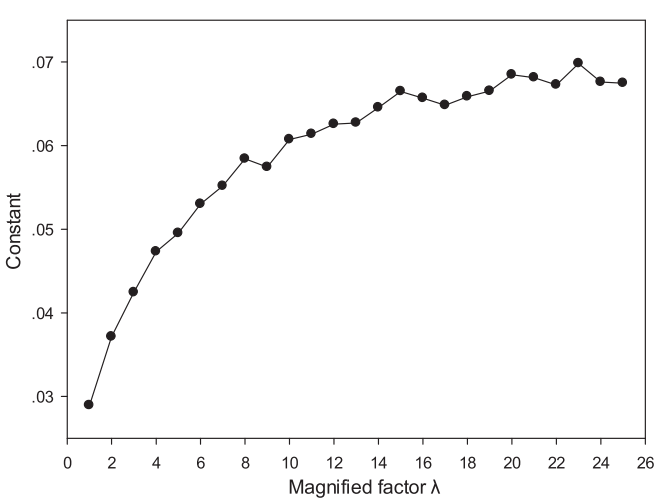

(f) The correlation coefficients of the constant

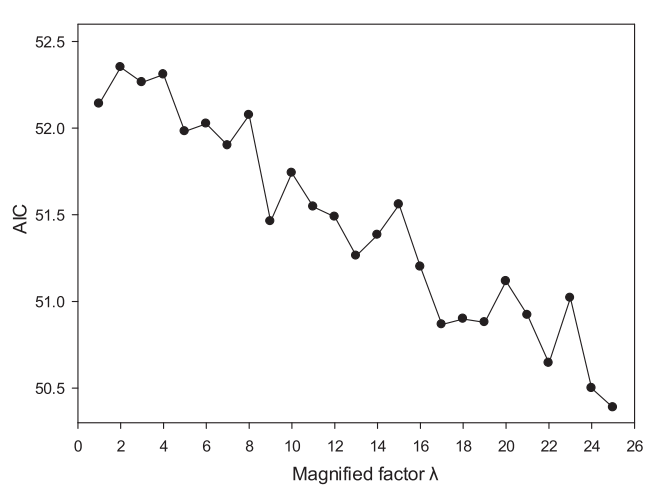

(h) AIC

Fig. 7. The variation of the coefficients and accuracy indicators with the magnified factor $\lambda$ in population-oriented modeling. 
Nevertheless, traditional spatial modeling takes the "pure" spatial relation such as adjacency or distance to measure the spatial interaction of counties rather than investigating into their administrative relation. The emergence of diversified types of counties such as urban districts and county-level cities has further pressed the necessity to embed administrative influence in spatial regression. This has implications for the driving mechanism of inter-city development as well as the institutional settings at the county level in urban agglomeration. In the future, apart from administrative influence, different spatial correlation factor such as accessibility, social network in the process of urbanization are also in an anticipation to be included to provide reference for policy-makers to strengthen the regional amalgamation in an all-around manner.

\section{Conclusions}

In the context of the proposition of the new-type urbanization in China, we decompose and measure urbanization from population-oriented and land-centered respects as well as unfold the underlying driving forces using Wuhan agglomeration as the case. The major contributions lie in the gauge on administrative influence, to be more specific, the status of urban district, countylevel city and county, through incorporating different spatial weight matrix in different scenarios. To be concluded, it is revealed that 1) both non-agricultural population and urban land exhibit significant spatial autocorrelation and the superiority in the city center is evident; 2) socio-economic development and transportation construction significantly influence urbanization whereas the fixed asset investment accounting for a large proportion being the most powerful factors; 3 ) different administrative status at the county level is an unneglectable factor and urban area has higher probability to expand when county-level city and urban district are adjacent; 4) the magnitude of this administrative status influence generally grows to a certain level and then reaches to a plateau. These findings provide theoretical basis for understanding the administrative dimension in new-type urbanization and have important policy implications on administrative adjustment and urban agglomeration.

\section{Acknowledgment}

This research is supported by the National Natural Science Foundation of China (41501179, 71573101), the National Funds for Distinguished Young Scientists (71225005) and the Key Projects of Philosophy and Social Sciences Research, Ministry of Education (14JZD009).

\section{References}

Abu, L. J., \& Hay, R. J. (2013). Third world urbanization. New York, U.S: Routledge.

Ali, R., \& Zhao, H. (2008). Wuhan, China and Pittsburgh, USA: urban environmental health past, present and future. Ecohealth, 5, 159-166.

Anselin, L. (2010). Thirty years of spatial econometrics. Papers in Regional Science, 89(1), 3-25.

Cartier, C. (2011). Urban growth, rescaling, and the spatial administrative hierarchy. Provincial China, 3(1)

Chan, K. W. (2010a). The household registration system and migrant labor in China: notes on a debate. Population and Development Review, 36(2), 357-364.

Chan, K. W. (2010b). Fundamentals of China's urbanization and policy. China Review: an Interdisciplinary Journal on Greater China, 10(1), 63-94.

Chan, K. W. (2012). Crossing the 50 percent population Rubicon: can China urbanize to prosperity? Eurasian Geography and Economics, 53(1), 63-86.

Chien, S. S. (2013). New local state power through administrative restructuring $-\mathrm{A}$ case study of post-Mao China county-level urban entrepreneurialism in Kunshan. Geoforum, 46, 103-112.

Chung, H. (2008). State regulation and China's administrative system: a spatial perspective. China review: an Interdisciplinary Journal on Greater China, 8(2), 201-230.

Cox, H. (2013). The secular city: Secularization and urbanization in theological perspective. Princeton University Press.
Crowley, G. R. (2012). Spatial dependence in constitutional constraints: the case of US states. Constitutional Political Economy, 23(2), 134-165.

Deng, X., Huang, J., Rozelle, S., \& Uchida, E. (2008). Growth, population and industrialization, and urban land expansion of China. Journal of Urban Economics, 63(1), 96-115.

Deng, X., Huang, J., Rozelle, S., \& Uchida, E. (2010). .Economic growth and the expansion of urban land in China. Urban Studies, 47(4), 813-843.

Fan, J., Liu, Y., Chen, T., Zhang, W. Z., Jin, F. J., \& Xu, Y. (2013). The key strategies and innovative thinking for optimization on spatial pattern of urbanization in China. Bulletin of the Chinese Academy of Sciences, 28(001), 20-27 (in Chinese).

Fan, S., Li, L., \& Zhang, X. (2012). Challenges of creating cities in China: lessons from a short-lived county-to-city upgrading policy. Journal of Comparative Economics, 40(3), 476-491.

Han, J., Hayashi, Y., Cao, X., \& Imura, H. (2009). Application of an integrated system dynamics and cellular automata model for urban growth assessment: a case study of Shanghai, China. Landscape and Urban Planning, 91(3), 133-141.

Han, S. S., \& Wu, X. (2004). Wuhan. Cities, 21(4), 349-362.

Hays, J. C., Kachi, A., \& Franzese, R. J. (2010). A spatial model incorporating dynamic, endogenous network interdependence: a political science application. Statistical Methodology, 7(3), 406-428.

Henderson, J. V. (2010). Cities and development. Journal of Regional Science, 50(1), $515-540$

Hsing, Y. (2010). The great urban transformation: Politics of land and property in China. Oxford University Press.

Kuang, W. (2011). Simulating dynamic urban expansion at regional scale in BeijingTianjin-Tangshan metropolitan area. Journal of Geographical Sciences, 21(2) 317-330.

LeSage, J. P. (1999). The theory and practice of spatial econometrics. Department of Economics, University of Toledo.

LeSage, J., \& Pace, R. K. (2008). Introduction to spatial econometrics. CRC press.

Li, L. (2011). The incentive role of creating "cities" in China. China Economic Review, 22(1), 172-181.

Lin, G. C., Li, X., Yang, F. F., \& Hu, F. Z. (2014). Strategizing urbanism in the era of neoliberalization: state power reshuffling, land development and municipal finance in urbanizing China. Urban Studies. http://dx.doi.org/10.1177/ 0042098013513644.

Lin, G. C., \& Yi, F. (2011). Urbanization of capital or capitalization on urban land? Land development and local public finance in urbanizing China. Urban Geography, 32(1), 50-79.

Liu, Y., Chen, J., Cheng, W., Sun, C., Zhao, S., \& Pu, Y. (2014). Spatiotemporal dynamics of the urban sprawl in a typical urban agglomeration: a case study on Southern Jiangsu, China (1983-2007). Frontiers of Earth Science, 8(4), 490-504.

Liu, Y. S., \& Yang, R. (2012). The spatial characteristics and formation mechanism of the county urbanization in China. ActaGeographicaSinica, 67(8), 1141-1150 (in Chinese).

Liu, Y., Yin, G., \& Ma, L. J. (2012). Local state and administrative urbanization in postreform China: a case study of Hebi City, Henan Province. Cities, 29(2), 107-117.

Ma, L. J., \& Wu, F. (2013). Restructuring the Chinese city: Changing society, economy and space. Routledge.

Moran, P. A. P. (1950). Notes on continuous stochastic phenomena 37. Biometrika, 37, $17-23$.

Ni, P. (2013). Annual report on China's urban competitiveness (No.11). Social Sciences Academic Press (in Chinese).

Ni, P., Kresl, P., \& Li, X. (2014). China urban competitiveness in industrialization: based on the panel data of 25 cities in China from 1990 to 2009. Urban Studies, 51(13), 2787-2805.

Peng, X. (2011). China's demographic history and future challenges. Science 333(6042), 581-587.

Seto, K. C., Güneralp, B., \& Hutyra, L. R. (2012). Global forecasts of urban expansion to 2030 and direct impacts on biodiversity and carbon pools. Proceedings of the National Academy of Sciences, 109(40), 16083-16088.

Shan, Z. R., \& Huang, Y. P. (2013). An analysis of the concepts, goals, contents, planning strategies and misunderstandings of new urbanization. Urban Planning Forum, 2, 16-22 (in Chinese).

Shen, J. (2008). Spatial strategies of urban development: rescaling and territorialization in post reform China. The Open Urban Studies Journal, 1, 11-18.

Shi, L., Li, D., \& Zhao, J. (2010). A method to estimate urban optimum population conditions: a case study of Xiamen, China. International Journal of Sustainable Development \& World Ecology, 17(4), 324-328.

Sun, C., Wu, Z. F., Lv, Z. Q., Yao, N., \& Wei, J. B. (2013). Quantifying different types of urban growth and the change dynamic in Guangzhou using multi-temporal remote sensing data. International Journal of Applied Earth Observation and Geoinformation, 21, 409-417.

Tan, R., Liu, Y., Liu, Y., He, Q., Ming, L., \& Tang, S. (2014). Urban growth and its determinants across the Wuhan urban agglomeration, central China. Habitat International, 44, 268-281.

The New Urbanization Planning of China (2014 - 2020) (in Chinese) (cited as UNP in the manuscript).

Torrens, P. M. (2008). A toolkit for measuring sprawl. Applied Spatial Anaysis and Policy, 1(1), 5-36.

Wang, W. (2011). Province-managing-county reform and public education spending: A quasi-natural Experiment of fiscal decentralization in China. Doctoral dissertation. University of Minnesota.

Wang, Y., Fang, C. L., \& Wang, Z. B. (2012). The study on comprehensive evaluation and urbanization division at county level in China. Geographical Research, 31(7) 
1305-1316 (in Chinese).

Wang, H., He, S., Liu, X., Dai, L., Pan, P., Hong, S., et al, (2013). Simulating urban expansion using a cloud-based cellular automata model: a case study of Jiangxia, Wuhan, China. Landscape and Urban Planning, 110, 99-112.

Wu, W., Zhang, W., Jin, F., \& Deng, Y. (2009). Spatio-temporal analysis of urban spatial interaction in globalizing China-a case study of Beijing-Shanghai Corridor. Chinese Geographical Science, 19(2), 126-134.

Xu, W. X. (2012). Research on intergovernmental relations of wuhan megalopolis Wuhan, China: Huazhong University of Science and Technology (Dissertation).

Yang, J., Song, G., \& Lin, J. (2014). Measuring spatial structure of China's megaregions. Journal of Urban Planning and Development. http://dx.doi.org/10.1061/ (ASCE) UP.1943-5444.0000207, 04014021.

Yeh, A. G., Xu, J., \& Liu, K. (2011). China's post-reform urbanization: Retrospect, policies and trends (Vol. 5). IIED.

Yew, C. P. (2012). Pseudo-Urbanization?Competitive government behavior and urban sprawl in China. Journal of Contemporary China, 21(74), 281-298.
Yu, D., \& Wei, Y. D. (2008). Spatial data analysis of regional development in Greater Beijing, China, in a GIS environment, Papers in Regional Science, 87(1), 97-117.

Zeng, C., Liu, Y., Stein, A., \& Jiao, L. (2015). Characterization and spatial modeling of urban sprawl in the Wuhan Metropolitan Area, China. International Journal of Applied Earth Observation and Geoinformation, 34, 10-24.

Zhao, P., Lü, B., \& Woltjer, J. (2009). Conflicts in urban fringe in the transformation era: an examination of performance of the metropolitan growth management in Beijing. Habitat international, 33(4), 347-356.

Zheng, Y. Chen, T. Cai, J. \& Liu, S. (2009). Regional concentration and region-based urban transition: China's mega-urban region formation in the 1990s. Urban Geography, 30(3), 312-333.

Zhou, Q., \& Sun, B. (2010). Analysis of spatio-temporal pattern and driving force of land cover change using multi-temporal remote sensing images. Science China Technological Sciences, 53(1), 111-119.

Zuo, X. (2008). China's decentralization and its impact on urbanization. Decentralization policies in asian development. World Scientific Publishing. 